\title{
Preface for Proceedings of the 8th International Symposium on Surface Science
}

\author{
Toshio Ogino* \\ Yokohama National University, Tokiwadai 79-5, Hodogaya-ku, Yokohama 240-8501, Japan
}

(Received 29 November 2018; Published 22 December 2018)

The 8th International Symposium on Surface Science (ISSS-8), which was organized by The Surface Science Society of Japan (SSSJ), Public Interest Incorporation Association, took place from October 22 to 26, 2017, at Tsukuba International Congress Center in Tsukuba, Japan. On behalf of the ISSS-8 organization committee, I would like to invite you to the collection of papers that were originally presented in ISSS-8. Scope of ISSS-8 includes eight basic sessions, Surface and Interface Structures, Surface Dynamics, Nanomaterials and Fabrication, Physical Properties, Characterization Methods, Surface Chemistry, Biosurfaces and Biointerfaces, and Green Technologies, and three topical ones, Advanced 2D Materials, Single Molecular Imaging and Manipulation, and Surfaces and Interfaces in Green Technologies.

In 1989, SSSJ organized the first international symposium, ISSS-1 - New Developments and Trends in Surface Science-, as the 10-year anniversary of the society. Through symposia in 1996 and 1999, SSSJ began to host the international symposium every three years from 2005. Today, ISSS is one of the largest international conferences in Japan in the field related to surface science and nanotechnology. In ISSS-8, we had 692 participants from 21 countries, 558 presentations, and 34 exhibition companies. Here, we have original research papers and review papers that have been accepted after peer review process and published in e-Journal of Surface Science and Nanotechnology.

Finally, we would like to thank all members of the publication committee, S. Aoyagi, publication chair, K. Akagi, A. Itakura, and F. Komori, publication vice-chairs, for their effort in the selection process of the contributed papers and editing this proceedings.

We hope you will be able to enjoy the excellent papers collected in this proceedings.

Sincerely,

Toshio Ogino

ISSS-8 Conference Chair

[DOI: $10.1380 /$ ejssnt.2018.A3]

\footnotetext{
* Corresponding author: ogino-toshio-rx@ynu.ac.jp
} 